J. Lake Sci. (湖泊科学), 2012, 24(4):629-636

http: //www. jlakes. org. E-mail: jlakes@niglas. ac.cn

(C) 2012 by Journal of Lake Sciences

\title{
$13.8 \mathrm{ka}$ 以来内蒙古吉兰泰盐湖的演化过程
}

\section{于志同 ${ }^{1,2}$, 刘兴起 ${ }^{2 * *}$, 王 永 $^{3}$, 葛兆帅 ${ }^{1}$, 潘存峰 ${ }^{4}$, 杨 波 $^{5}$}

(1: 江苏师范大学城市与环境学院, 徐州 221116)

(2: 中国科学院南京地理与湖泊研究所湖泊与环境国家重点实验室, 南京 210008)

(3: 中国地质科学院地质研究所, 北京 100037)

( 4 : 内蒙古中盐吉兰泰盐化集团公司,阿拉善 750333)

(5:中国科学院青海盐湖研究所,西宁 810008)

摘 要: 通过系统分析吉兰泰盐湖 JLT-2010 孔蒸发盐类矿物、碳酸盐矿物、碎屑岩矿物等, 结合 $\mathrm{AMS}^{14} \mathrm{C}$ 测年获得的年代 序列, 研究该湖 $13.8 \mathrm{ka}$ 以来的演化过程. 结果表明: 吉兰泰盐湖 13.8-11.7 cal ka BP 期间水体较淡;11.7-10.2 cal ka BP 期间湖泊开始萎缩、咸化, 进人咸水湖阶段; $10.2-5.5 \mathrm{cal} \mathrm{ka} \mathrm{BP}$ 期间湖泊进入硫酸盐沉积阶段, 其中 9.0 - $8.2 \mathrm{cal} \mathrm{ka}$ $\mathrm{BP}$ 经历了一个明显的淡化过程; $5.5 \mathrm{cal} \mathrm{ka} \mathrm{BP}$ 以来, 湖泊成盐作用进一步加强, 由前期的硫酸盐沉积转变为氯化物沉积, 其中 3.7-2.0 cal ka BP 达到全面氯化物沉积阶段, 2.0-1.7 cal ka BP 又经历了一个短暂而明显的淡化过程; 目前, 该盐 湖已进人干盐湖发展阶段. 总体而言, 吉兰泰盐湖蒸发盐类矿物主要是在全新世增温的背景条件下逐步萎缩形成的, 由 于区域性干旱气候的持续影响,吉兰泰盐湖逐步萎缩、咸化,进而析盐.

关键词: 吉兰泰盐湖; 矿物组成; 演化过程

\section{Evolution of Jilantai Salt Lake, Inner Mongolia in the last $13.8 \mathrm{ka}$}

\author{
YU Zhitong ${ }^{1,2}$, LIU Xingqi ${ }^{2}$, WANG Yong ${ }^{3}$, GE Zhaoshuai ${ }^{1}$, PAN Cunfeng ${ }^{4} \&$ YANG Bo $^{5}$ \\ (1: School of Urban and Environmental Sciences, Jiangsu Normal University, Xuzhou 221116, P. R. China) \\ (2: State Key Laboratory of Lake Science and Environment, Nanjing Institute of Geography and Limnology, Chinese Academy \\ of Sciences, Nanjing 210008, P. R. China) \\ (3: Institute of Geology, Chinese Academy of Geological Sciences, Beijing 100037, P. R. China) \\ (4: Jilantai Salt Group Co., Ltd. , Lantai Salt Division, Inner Mongolia, Alxa 750333, P. R. China) \\ (5: Qinghai Institute of Salt Lakes, Chinese Academy of Sciences, Xining 810008, P. R. China)
}

\begin{abstract}
Evolution of Jilantai Salt Lake in the last $13.8 \mathrm{ka}$ was reconstructed based on the analysis of evaporate minerals, carbonate minerals and detrital minerals from the core JLT-2010. The lake water was fresh or slightly salty between 13.8 and 11.7 cal ka BP. The lake began to shrink between 11.7 and $10.2 \mathrm{cal} \mathrm{ka} \mathrm{BP}$, and then it entered into the lagoon stage. Sulfate deposition occurred in Jilantai Salt Lake between 10.2 and 5.5 cal ka BP, meanwhile, from 9.0 to 8.2 cal ka BP there existed a significant desalination process. The lake reached full chloride deposition stage between 3.7 and 2.0 cal ka BP, and a short and obvious desalt period occurred between 2.0 and $1.7 \mathrm{cal} \mathrm{ka} \mathrm{BP.} \mathrm{Overall,} \mathrm{evaporate} \mathrm{minerals} \mathrm{appeared} \mathrm{just} \mathrm{at} \mathrm{the} \mathrm{beginning} \mathrm{of} \mathrm{the} \mathrm{Holocene} \mathrm{when}$ temperature increased relative to the late glacial. As the regional arid climate continually affecting the area, Jilantai Salt Lake gradually shrank and salinized.
\end{abstract}

Keywords: Jilantai Salt Lake; mineral composition; evolution

研究过去气候环境演变的过程与规律, 目的是认识现代气候环境在演变历史中所处的位置, 为预测未 来气候变化趋势提供科学依据 ${ }^{[1]}$. 在全球环境变化研究中, 湖泊沉积物具有连续、敏感和高分辨的特点 ${ }^{[2]}$, 日益受到相关研究者的重视. 盐湖一般由淡水湖一咸水湖演变而来, 自其成生始, 在其发展的各个阶段都详

* 中国地质调查局地质调查项目(1212011087116) 资助. 2011-12-19 收稿;2012-02-20 收修改稿. 于志同,男, 1985 年生, 硕士研究生;E-mail:yzt1985tong@ 126.com.

** 通信作者; E-mail: xqliu@ niglas. ac. cn. 
尽地保存着周围环境变化的信息 ${ }^{[3]}$. 盐湖沉积是特定自然地理和地质环境的产物, 对古气候和古环境变化 反应灵敏 ${ }^{[4-9]} .1970 \mathrm{~s}-1980 \mathrm{~s}$ 美国、加拿大、澳大利亚等国针对不同地区的盐湖开展了古气候、古环境演化等 方面的研究 ${ }^{[10-13]}$. 中国这方面的研究始于 $1980 \mathrm{~s}$ 中期, 国内众多单位曾先后在柴达木盆地 ${ }^{[14-19]}$ 、西藏 ${ }^{[20-22]}$ 、 内蒙古 ${ }^{[23-25]}$ 、新疆等地区的盐湖进行了古气候及古环境演化的研究工作, 获得了丰富的科学积累, 为过去全 球变化的研究提供了宝贵的区域对比资料.

吉兰泰盐湖处于干旱一半干旱、季风一非季风过渡区,生态环境极其脆弱, 湖泊沉积记录对环境变化极 为敏感, 该地区存在着保存较好的一系列湖岸堤和广泛分布的软体动物壳体, 是古湖演化和古环境变化研 究的良好对象 ${ }^{[26]}$. 吉兰泰盐湖的演化过程与区域气候、环境变化乃至全球变化都密切相关. 1980s 末以来, 国内众多学者根据吉兰泰盐湖盐类沉积特征、盐湖的地貌特征以及周边的阶地等均开展了大量的研究, 并 结合必要的测年数据, 探讨了吉兰泰盐湖的演化过程 ${ }^{[26-32]}$. 但是相关工作由于测年数据较少, 故而精度欠 缺, 使得对于吉兰泰盐湖演化过程的探讨存在一定的不确定性. 为此,本文将依据吉兰泰盐湖中部获得的钻 孔岩芯材料, 在 $\mathrm{AMS}^{14} \mathrm{C}$ 测年的基础上, 采用定量一半定量的 XRD 矿物分析方法, 系统分析盐湖形成过程中 的矿物组合特征, 揭示 $13.8 \mathrm{ka}$ 以来该盐湖的演化过程.

\section{1 研究区概况}

吉兰泰盐湖 $\left(39^{\circ} 36^{\prime} \sim 39^{\circ} 48^{\prime} \mathrm{N}, 105^{\circ} 34^{\prime} \sim 105^{\circ} 49^{\prime} \mathrm{E}\right)$ 坐落于内蒙古自治区阿拉善盟阿拉善左旗北部的 吉兰泰镇. 盐湖周围的地形具有明显的环带状分布特征, 从山顶到盐湖中心分别为基岩山地、山前倾斜平 原、古湖积倾斜平原和沙漠带, 以及干盐滩. 湖面海拔 $1017 \sim 1023 \mathrm{~m}$, 面积约 $120 \mathrm{~km}^{2}$. 湖区处于西北内陆季 风边缘区, 气候干燥, 年平均气温 $9.5^{\circ} \mathrm{C}$, 最高气温 $40.9^{\circ} \mathrm{C}$, 最低温度 $-32.2^{\circ} \mathrm{C}$, 年较差、日较差温度都大; 年 平均降水量 $115 \mathrm{~mm}$, 年蒸发量 $3036 \mathrm{~mm}$, 经常刮西北风,一般风速 $3.5 \mathrm{~m} / \mathrm{s}$, 属于多风沙少降水、蒸发强烈的 大陆性干旱气候. 湖区的水系极不发育, 植被多为耐旱、耐碱的小灌木及草本植物. 盐类沉积位于盐湖的东 北部, 呈 NE-SW 走向, 长 $9.66 \mathrm{~km}$, 宽 $6.4 \mathrm{~km}$, 面积约 $37.19 \mathrm{~km}^{2}$. 矿层产状水平, 矿体连续, 厚度一般 $3 \sim 4 \mathrm{~m}$, 最厚可达 $5.92 \mathrm{~m}$. 化学沉积以石盐为主, 其次为芒硝和石膏. 水化学类型属硫酸盐型硫酸镁亚型, 这种类型 的盐湖及盐类沉积广泛分布于中国内陆盐湖区. 石盐探明储量为 $1.1 \times 10^{8} \mathrm{t}$, 是内蒙古自治区规模最大的盐 类矿床 ${ }^{[29,33-34]}$.

\section{2 样品的采集与分析测试}

\section{1 样品的采集}

2010 年 10 月,使用 XY-1B 型钻机, 在吉兰泰盐湖近湖心处获得钻孔一口 ( JLT-2010), 孔深 $28.01 \mathrm{~m}$, 孔 径 $108 \mathrm{~mm}$. 岩芯运回实验室, 以 $1 \mathrm{~cm}$ 或 $2 \mathrm{~cm}$ 间距进行分样. 本文以 JLT-2010 孔上部 $787 \mathrm{~cm}$ 的沉积岩芯为 研究对象,现将该段岩性特征自下而上简述如下:

$787 \sim 660 \mathrm{~cm}$ : 浅灰绿色砂; 660 563 cm: 浅灰绿色泥质粉砂, 局部夹杂石膏等少量盐; 563 510 cm: 灰 褐色细砂夹石盐, 石盐颗粒状, 粒径大多 $0.2 \mathrm{~cm}$ 左右, 最大可达 $2 \mathrm{~cm} ; 510 \sim 426 \mathrm{~cm}$ : 粉砂质泥岩夹中细粒石 盐, 颜色由底向上逐渐加深, 底部 $40 \mathrm{~cm}$ 含少量石盐, 石膏发育, 结晶良好, 棱柱状, 长度 $0.5 \sim 2.0 \mathrm{~cm}$; $426 \sim 406 \mathrm{~cm}$ : 粉砂质泥岩, 含有较多白色矿物; $406 \sim 82 \mathrm{~cm}$ : 中细一中粗粒石盐层, 较致密, 含灰黑色泥、结晶 良好的石膏等; $82 \sim 0 \mathrm{~cm}$ : 中细粒石盐夹黄褐色泥质粉砂,较致密.

\section{2 样品分析测试}

2.2. $1 \mathrm{AMS}^{14} \mathrm{C}$ 年代的测定 JLT-2010 岩芯 $\mathrm{AMS}^{14} \mathrm{C}$ 年代测试在新西兰国家同位素测试中心拉夫特放射性实 验室完成,采用 8 个样品进行测定,测年材料为沉积物中的总有机质.

2.2.2 矿物分析 对 JLT-2010 孔 $787 \mathrm{~cm}$ 以上的岩芯进行系统的矿物分析测试. 选取部分经 $40^{\circ} \mathrm{C}$ 烘干研磨 至 100 目左右的样品, 在中国科学院青海盐湖研究所利用荷兰飞利浦公司的 X-pert Pro 型粉晶 X 射线衍射 仪,进行矿物种类及相对百分含量的测定.

实验条件为: 石墨单色滤波器, $\mathrm{Cu}$ 靶 $K_{\alpha}$ 辐射 $(\lambda=1.5406 \AA)$. 扫描角度 $(2 \theta)$ 为 $10 \sim 80^{\circ}$, 扫描速度为 $5 \%$ min. 矿物种类的检出及相对百分含量的确定由该仪器自带的软件 X'Pert HighScore Plus 完成.

样品中不同矿物的重量百分数采用 Chung ${ }^{[35]}$ 提出的方法进行计算, 公式为: 


$$
X_{i}=\left(\frac{K_{i, n}}{I_{i, n}} \sum_{j=1}^{m} \frac{I_{j, n}}{K_{j, n}}\right)^{-1}
$$

式中, $X_{i}$ 为样品中 $i$ 矿物重量百分数, $K_{i, n}$ 和 $K_{j, n}$ 是矿物 $i$ 和 $j$ 分别在衍射线 $n$ 上的参照强度比值, $I_{i, n}$ 和 $I_{j, n}$ 是 矿物 $i$ 和 $j$ 分别在衍射线 $n$ 上的积分强度, $m$ 是样品中所有矿物的个数.

\section{3 年代序列的建立}

沉积年代用 8 个样品年代加以控制. 接近地表 (深度 $6 \sim 8 \mathrm{~cm}$ ) 的 $\mathrm{AMS}^{14} \mathrm{C}$ 年龄为 $1593 \mathrm{a} \mathrm{BP}$, 所测年龄偏 老(表 1, 图 1). 其原因可能有两个: (1) 沉积物存在沉积间 断 $^{[36-37]}$; (2) 由 “硬水效应”造成. 据调查,20 世 纪 50 年代末 60 年代初期,该湖尚有 $0.1 \sim 0.2 \mathrm{~m}$ 的湖表卤水,加上该孔 $5 \mathrm{~m}$ 以上岩芯没有沉积间断的迹象, 说明吉兰泰盐湖出现上千年沉积间断的可能性较小. 由于中国西部干旱区湖泊的 $\mathrm{AMS}^{14} \mathrm{C}$ 年代普遍存在“硬 水效应”, 如青海湖存在 1039 a 的硬水效应 ${ }^{[38]}$; 西藏 Ahung Co 的硬水效应为 $600 \sim 700 \mathrm{a}^{[37]}$; 茶卡盐湖的硬 水效应为 $1700 \mathrm{a}^{[18-19]}$; 萨音乌苏湖的硬水效应为 $1080 \mathrm{a}^{[39]}$. 故而推断吉兰泰盐湖可能存在 $1593 \mathrm{a}$ 的硬水效 应. 为此,统一将 8 个 $\mathrm{AMS}^{14} \mathrm{C}$ 年代减去 $1593 \mathrm{a}$, 之后再利用 Calib 6.0.2 程序将经过 “硬水效应” 校正的 $\mathrm{AMS}^{14} \mathrm{C}$ 年龄转换为日历年龄 (表 1). 经推算, 岩芯 $787 \mathrm{~cm}$ 处的年龄为 $13.8 \mathrm{cal} \mathrm{ka} \mathrm{BP}$ 左右.

表 1 吉兰泰盐湖 JLT-2010 孔 $\mathrm{AMS}^{14} \mathrm{C}$ 及日历年龄

Tab. 1 AMS $^{14} \mathrm{C}$ dates and calendar ages of the core JLT-2010 in Jilantai Salt Lake

\begin{tabular}{ccccccc}
\hline $\begin{array}{c}\text { 样品 } \\
\text { 编号 }\end{array}$ & $\begin{array}{c}\mathrm{Lab} \\
\text { I. D. }\end{array}$ & $\begin{array}{c}\text { 深度 } \\
/ \mathrm{cm}\end{array}$ & $\begin{array}{c}\mathrm{AMS}^{14} \mathrm{C} \text { 年龄 } \\
/ \mathrm{a} \mathrm{BP}\end{array}$ & $\begin{array}{c}\delta^{13} \mathrm{C} \\
/ \%\end{array}$ & $\begin{array}{c}\text { 扣除 } 1593 \mathrm{a} \text { 后的 } \\
\mathrm{AMS}^{14} \mathrm{C} \text { 年龄/a BP }\end{array}$ & $\begin{array}{c}\text { 日历年龄 } \\
/ \text { cal a BP }\end{array}$ \\
\hline JLT-1-8 & 32883 & $6 \sim 8$ & $1593 \pm 20$ & -33.9 & $0 \pm 20$ & $-4 \sim 245(120)$ \\
JLT-2-11 & $32721 / 1$ & $67 \sim 69$ & $3415 \pm 35$ & -21.9 & $1822 \pm 35$ & $1751 \sim 1813(1782)$ \\
JLT-4-31 & $32721 / 2$ & $200 \sim 201$ & $5156 \pm 20$ & -20.4 & $3563 \pm 20$ & $3839 \sim 3884(3861)$ \\
JLT-5-25 & $32721 / 3$ & $272 \sim 274$ & $5311 \pm 20$ & -19.1 & $3718 \pm 20$ & $3993 \sim 4039(4016)$ \\
JLT-6-21 & $32713 / 1$ & $326 \sim 328$ & $6468 \pm 40$ & -20.0 & $4875 \pm 40$ & $5589 \sim 5622(5605)$ \\
JLT-6-27 & $32721 / 4$ & $338 \sim 340$ & $7015 \pm 40$ & -22.5 & $5422 \pm 40$ & $6208 \sim 6254(6231)$ \\
JLT-8-30 & $32721 / 5$ & $474 \sim 476$ & $9246 \pm 35$ & -19.1 & $7653 \pm 35$ & $8401 \sim 8457(8429)$ \\
JLT-15-16 & $32721 / 6$ & $936 \sim 938$ & $14886 \pm 50$ & -22.1 & $13293 \pm 50$ & $16123 \sim 16656(16389)$ \\
\hline
\end{tabular}
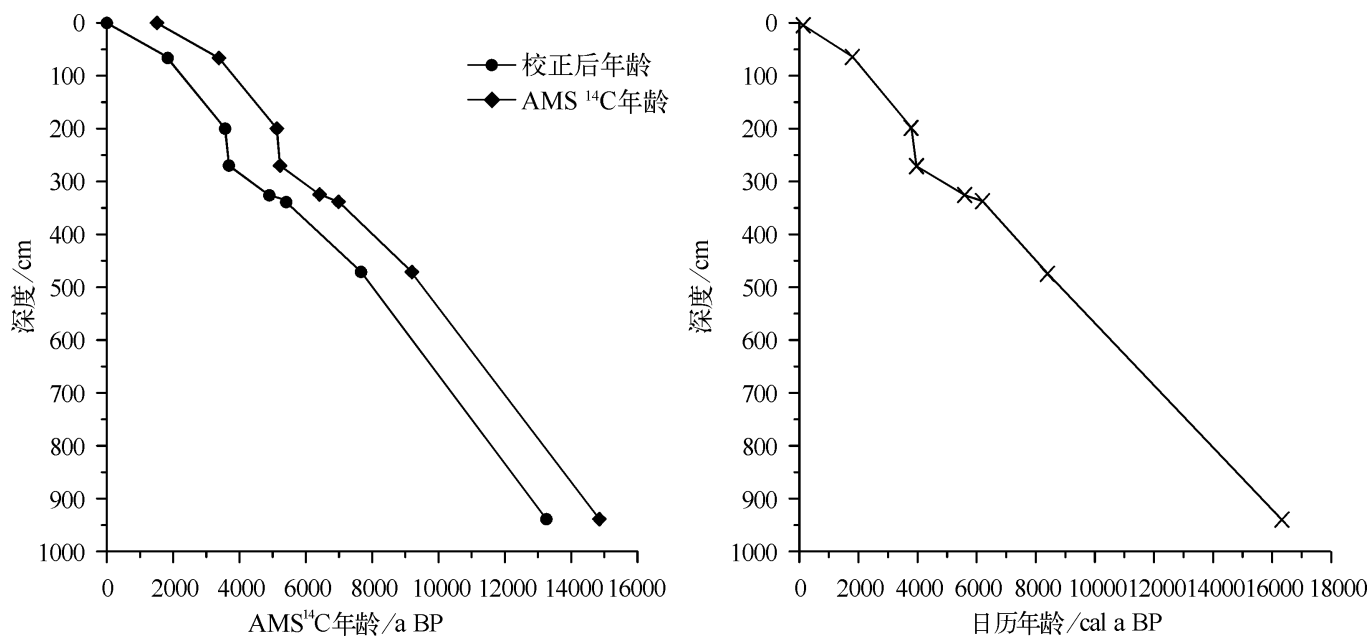

图 1 吉兰泰盐湖 JLT-2010 孔年代与深度的关系

Fig. 1 Relationship between depth and age in the core JLT-2010 of Jilantai Salt Lake 


\section{$413.8 \mathrm{ka}$ 以来吉兰泰盐湖的演化过程}

XRD 分析表明,JLT-2010 孔中的碎屑岩矿物主要由石英、白云母、斜绿泥石、长石等组成; 碳酸盐矿物主 要由方解石和白云石两种构成; 检出的盐类蒸发矿物主要有石盐 $(\mathrm{NaCl})$ 、石膏 $\left(\mathrm{CaSO}_{4} \cdot 2 \mathrm{H}_{2} \mathrm{O}\right)$ 、钻芒硝 $\left(\mathrm{Na}_{2} \mathrm{SO}_{4} \cdot \mathrm{CaSO}_{4}\right)$ 、芒硝 $\left(\mathrm{Na}_{2} \mathrm{SO}_{4} \cdot 10 \mathrm{H}_{2} \mathrm{O}\right)$ 、白钠镁矾 $\left(\mathrm{Na}_{2} \mathrm{Mg}\left(\mathrm{SO}_{4}\right)_{2} \cdot 4 \mathrm{H}_{2} \mathrm{O}\right)$, 另外还有少量的泻利盐 $\left(\mathrm{MgSO}_{4} \cdot 7 \mathrm{H}_{2} \mathrm{O}\right)$ 等. 肉眼和显微镜下观察这些蒸发盐矿物和碳酸盐矿物结晶均很好, 说明它们大都是自生 的, 未经后期改造. 根据 JLT-2010 孔沉积物和矿物组成的变化, 将吉兰泰盐湖 $13.8 \mathrm{ka}$ 以来的湖泊演化过程 讨论如下(图 2):

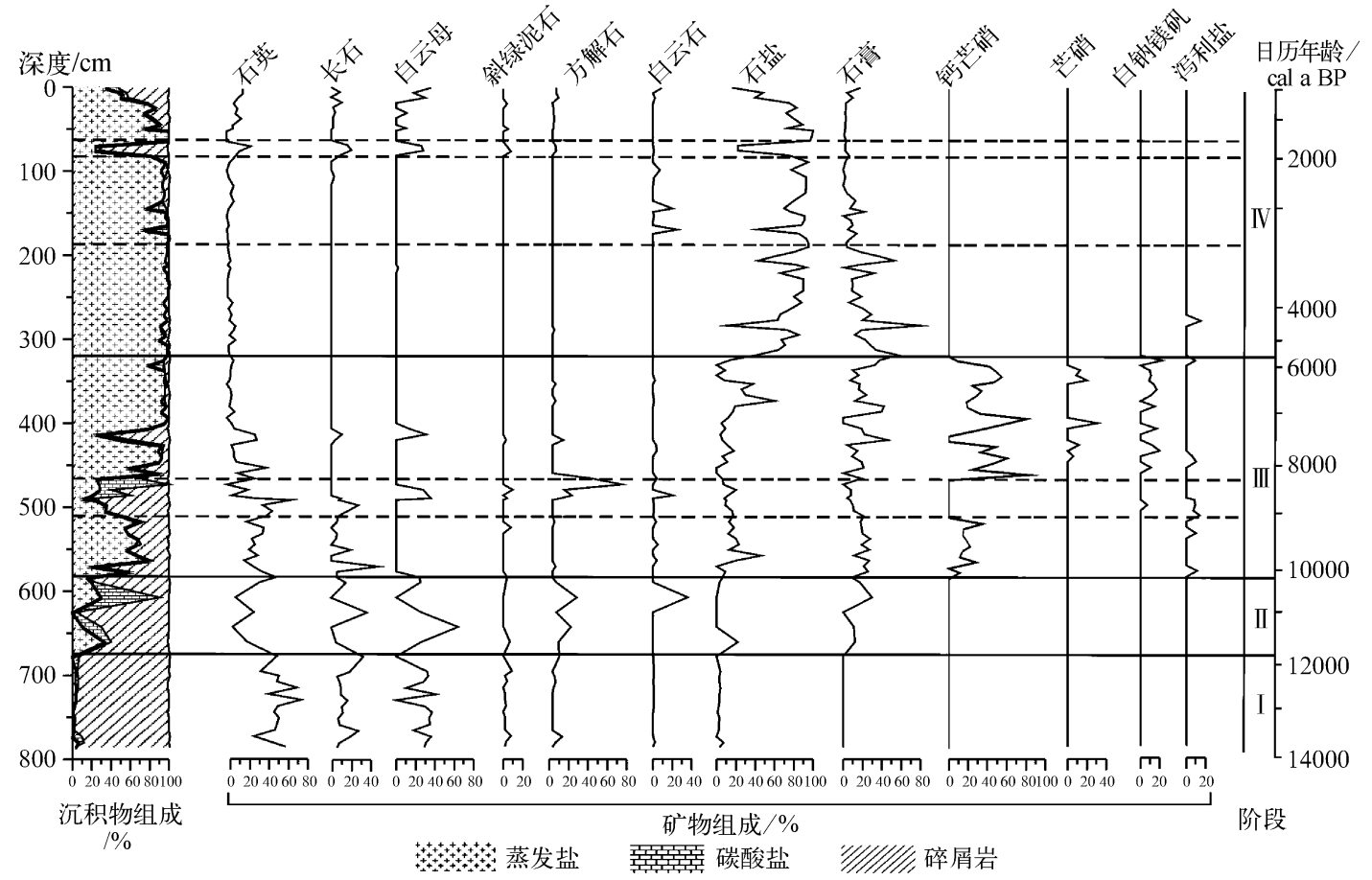

图 2 吉兰泰盐湖 JLT-2010 孔沉积物矿物组成变化

Fig. 2 Variation in mineral composition in the core JLT-2010 of Jilantai Salt Lake

（1）阶段 I ( 787 667 cm;13.8-11.7 cal ka BP) : 淡水一微(半) 咸水阶段.沉积物为浅灰褐色砂及浅灰 绿色泥质粉砂,碎屑岩成分高达 $95 \%$, 其中石英占 $52 \%$ 左右,长石和粘土类矿物占 $43 \%$ 左右, 碳酸盐矿物占 $2 \%$ 左右, 几乎无其它盐类矿物.上述矿物组合说明,此时水体较淡,湖泊处于淡水一微(半) 咸水阶段.

（2）阶段 II (667 578 cm;11.7-10.2 cal ka BP) : 咸水湖阶段. 沉积物为浅灰绿色泥质粉砂,碎屑岩成 分占 $66 \%$, 蒸发盐类矿物占 $18 \%$, 碳酸盐矿物占 $16 \%$ 左右. 此时的盐类矿物以石膏为主,含量波动于 $9 \%$ $30 \%$ 之间,平均为 $13 \%$; 石盐含量略有增加, 达到 5\% 左右. 石膏的出现、石盐的增加以及碎屑岩类矿物的降 低,表明此时的吉兰泰湖开始萎缩,盐度有所升高, 湖泊处于咸水湖阶段.

（3）阶段 III $(578 \sim 324 \mathrm{~cm} ; 10.2-5.5 \mathrm{cal} \mathrm{ka} \mathrm{BP})$ : 硫酸盐沉积阶段. 沉积物底部为灰褐色细砂夹盐, 上 部为粉砂质泥岩夹中细粒盐,该阶段碎屑岩成分急剧降低到 $27 \%$ 左右, 碳酸盐矿物的含量为 $6 \%$, 而蒸发盐 类矿物的含量增加到 $67 \%$. 其中硫酸盐类矿物的含量达 $52 \%$ 左右, 表明同第 II 阶段相比,该阶段湖水的盐度 进一步增高, 吉兰泰盐湖进人了硫酸盐沉积阶段.

早期 (578 512 cm;10.2-9.0 cal ka BP) : 沉积物中的盐类矿物大量增加,已达 60\% 左右,盐类矿物中 除石膏的含量进一步增加到 22\% 左右,还大量出现了钙芒硝,其含量在 12\% 38\% 之间波动,均值达 $19 \%$, 
同时石盐含量也增高到 $17 \%$ 左右. 相应地碎屑岩矿物逐步降低到 $20 \% \sim 45 \%$ 左右, 此时碳酸盐矿物已不足 $2 \%$. 钲芒硝的大量出现, 石盐、石膏的进一步增加, 同时碳酸盐含量的大量减少, 表明吉兰泰盐湖进一步萎 缩, 主要处于硫酸盐沉积阶段.

中期 (512 465 cm;9.0-8.2 cal ka BP) : 盐类矿物含量急剧下降至不足 30\%, 以少量的石膏和石盐为 主, 钙芒硝消失. 碎屑岩矿物的含量增至 51\% 左右, 其中石英占 $31 \%$ 左右, 长石及粘土矿物等占 $20 \%$ 左右, 与此同时, 碳酸盐矿物的含量也增加到 $20 \%$ 左右, 表明此时的吉兰泰盐湖经历了一个明显的淡化过程.

晚期 (465 324 cm;8.2-5.5 cal ka BP) : 蒸发盐类矿物占据主导地位 ( $86 \%$ 左右), 碎屑岩矿物 ( $12 \%$ 左 右) 及碳酸盐矿物 ( < 2\% ) 急剧减少. 盐类矿物以钙芒硝 ( $41 \%$ 左右) 为主, 含少量石膏 ( $19 \%$ 左右)、石盐 (14\% 左右) 及白钠镁矾 ( $8 \%$ 左右), 此外还伴有少量的芒硝和泻利盐出现. 碎屑岩矿物中粘土矿物及长石等 和碳酸盐矿物几乎消失. 此时吉兰泰盐湖再次萎缩, 盐度进一步升高, 盐湖达到硫酸盐沉积旺盛阶段.

(4) 阶段 IV (324 0 cm;5.5 cal ka BP 以来) : 氯化物沉积阶段. 沉积物主要为中细一中粗粒石盐层, 期 间夹有薄层粉砂质泥岩层等, 蒸发盐类矿物高达近 $90 \%$, 而碎屑岩矿物和碳酸盐矿物仅余 $10 \%$ 左右. 盐类矿 物以石盐 $(74 \%$ 左右) 和石膏 (14\% 左右)为主,表明此时的吉兰泰盐湖已进人氯化物沉积阶段.

早期(324 191 cm;5.5-3.7 cal ka BP) : 成盐作用的进一步加强,使得该阶段蒸发盐类矿物增至 97\%， 碎屑岩和碳酸盐矿物几乎消失. 盐类矿物以石盐 $(70 \%$ 左右)为主,而钙芒硝、芒硝、白钠镁矾、泻利盐等矿物 均已消失, 表明此时的吉兰泰盐湖进一步萎缩,盐度继续升高,盐湖已进人氯化物沉积阶段.

中期 (191 81 cm;3.7-2.0 cal ka BP) : 蒸发盐类矿物主要为石盐,含量在 70\% 95\%, 平均高达 $85 \%$; 石膏进一步减少, 含量不足 7\% ; 而碎屑岩矿物、碳酸盐矿物及其它盐类矿物基本消失, 表明吉兰泰盐湖已进 人全面的氯化物沉积阶段.

晚期 (81 0 cm;2.0 cal ka BP 以来) : 盐湖的析盐能力逐步降低, 碎屑岩成分逐步增多. 期间 ( $81 \sim$ $65 \mathrm{~cm} ; 2.0-1.7 \mathrm{cal} \mathrm{ka} \mathrm{BP}$ ), 盐类矿物含量急剧下降, 不足 $25 \%$, 仍以石盐为主; 碎屑岩矿物增至 71\% 左右, 其中长石和粘土矿物等含量达 $52 \%$; 碳酸盐矿物 $4 \%$ 左右. 表明此时的吉兰泰盐湖经历了一个短暂而明显的 淡化过程. 随后 (65 0 cm;1.7 cal ka BP 以来), 整体上呈现蒸发盐类矿物逐年减少, 碎屑岩矿物逐年增多的 趋势. 吉兰泰盐湖仍处于氯化物沉积阶段,但成盐作用开始逐步减弱 (图 2).

目前, 吉兰泰盐湖已经演化到干盐湖发展阶段. 20 世纪 50 年代末 60 年代初期,该湖尚有 $0.1 \sim 0.2 \mathrm{~m}$ 的湖表卤水;1983 年 5-6 月份中国科学院青海盐湖研究所在该湖考察时,实测晶间卤水水位已经低于湖面 $0.1 \sim 0.3 \mathrm{~m}$, 尤其是湖盆边缘水位下降的更明显 ${ }^{[28,33]}$.

\section{5 区域对比与讨论}

晚冰期中晚期, 吉兰泰湖为淡水一微 (半) 咸水湖,这与前人的研究结果 ${ }^{[26-32]}$ 基本一致. 另外,该湖与邻 近的青海湖、茶卡盐湖等也具有很大的相似性 ${ }^{[18-19,38,40]}$. 茶卡盐湖的研究表明 ${ }^{[18-19]}$, 晚冰期期间, 茶卡湖为淡 水湖而未出现咸化,可能同冰融水的补给有关. 青海湖的研究表明 ${ }^{[38,40]}$, 晚冰期期间青海湖高湖面的出现同 气候转暖导致冰川消融有关.

全新世以来,内蒙西部湖泊迅速向盐湖方向转化;而中、东部湖泊原来收缩幅度较大,且面积较小的湖 泊也向盐湖方向发育, 那些在收缩中仍保持有一定水域的较大湖泊则向咸水湖演化, 如岱海、达妻诺尔等咸 水湖 ${ }^{[41]}$.

吉兰泰湖区进人全新世以后,气候环境持续向干旱化方向发展, 该湖逐步萎缩, 盐度不断增高, 成盐作 用不断加强, 尤其是全新世中期以来, 盐湖的萎缩咸化进一步加剧, 最终发育成大型的盐湖矿床. 这种演化 模式与青海茶卡盐湖 ${ }^{[18-19]}$ 的记录基本一致. 茶卡盐湖的研究表明 ${ }^{[18-19]}, 11.7-5.9 \mathrm{cal} \mathrm{ka} \mathrm{BP}$, 该湖逐步萎缩, 进人硫酸盐沉积阶段; 5.9-5.25 cal ka BP, 经历了一个明显的淡化过程;5.25-0 cal ka BP, 盐湖再次萎缩, 达到氯化物沉积阶段.

一些来自中国西部不同载体的古气候资料, 如青海湖 ${ }^{[38,40]}$ 、色林错 ${ }^{[42-43]}$ 、班戈错 ${ }^{[44-45]}$ 、龙木 - 松西 错 ${ }^{[44,46]}$ 、黄土高原 ${ }^{[47]}$ 等的记录均表明, 全新世中早期时的气候要比现在温暖潮湿. 然而, 吉兰泰盐湖却在进 人全新世时湖泊开始萎缩,逐步咸化,10.2-9.0 cal ka BP 期间已出现硫酸盐沉积,说明全新世早期吉兰泰 
湖区气候干旱.

在全新世大暖期 $(8.5-3.0 \mathrm{ka} \mathrm{BP}$ ) 期间, 中国大部分地区气候以高温多雨为特征,夏季风增强, 被称之 为气候适宜期 ${ }^{[48-49]}$. 此时, 中国西部普遍出现高湖面 ${ }^{[50-54]}$; 蒙古北部许多湖泊在全新世中期也存在高湖 面 ${ }^{[55-57]}$. 吉兰泰盐湖在 $(9.0-8.2 \mathrm{cal} \mathrm{ka} \mathrm{BP})$ 期间有一个短暂的淡化期,随后 $(8.2-5.5 \mathrm{cal} \mathrm{ka} \mathrm{BP})$ 湖泊逐步 萎缩, 盐度逐步增高. 同处于亚洲季风边缘区的巴丹吉林沙漠居延泽、腾格里沙漠潴野泽、头道湖、野麻湖、 毛乌素沙漠盐海子等在全新世中期均经历了湖泊缩小甚至干涸过程 ${ }^{[8-61]}$. 以上表明, 全新世中期腾格里沙 漠一吉兰泰一毛乌素沙漠这一季风边缘区域气候干旱, 吉兰泰湖区出现了中全新世干旱事件. 亚洲夏季风增 强, 吉兰泰湖区干旱程度却进一步增加, 一种解释为夏季风增强所带来的降水量的增加量小于温度升高造 成的蒸发量的增加量 ${ }^{[18-19]}$, 说明影响此区域气候的因素不仅仅是亚洲夏季风, 可能还与西风环流、局地气 流、古水文状况等的综合作用有关,从而显示了吉兰泰盐湖由于地理位置决定的特殊性.

另外,一些研究表明, $6.0 \mathrm{cal} \mathrm{ka} \mathrm{BP}$ 以后, 亚洲夏季风开始减弱, 引起气候的变冷和转干 ${ }^{[38,40,62-64]}$. 吉兰 泰湖在 $5.5 \mathrm{cal} \mathrm{ka} \mathrm{BP}$ 以后, 石盐大量析出, 湖泊极度咸化萎缩, 说明此时段内该湖区气候干旱程度加剧, 亚 洲夏季风的减弱可能与吉兰泰湖区的干旱化有着密切的关系.

\section{6 结论}

吉兰泰盐湖 JLT-2010 孔沉积物矿物组成的变化, 记录了该湖 $13.8 \mathrm{ka}$ 以来的湖泊演化过程. 晚冰期阶 段, 吉兰泰盐湖水体较淡, 后期水体咸度逐渐增大; 伴随着全新世的到来, 该湖逐步萎缩, 盐度不断增高, 成 盐作用不断加强, 尤其是全新世中期以来, 盐湖的萎缩咸化进一步加剧. 总体而言, 吉兰泰盐湖盐类矿物的 出现主要是在全新世增温的背景条件下逐步萎缩形成的, 区域性干旱气候在吉兰泰盐湖的形成演化过程中 起着重要的作用.

\section{7 参考文献}

[ 1 ] 曹建廷, 王苏民, 沈 吉等. 近千年来内蒙古岱海气候环境演变的湖泊沉积记录. 地理科学, 2000, 20 (5): 391-396.

[2] 王苏民, 冯 敏. 内蒙古岱海湖泊环境变化与东南季风强弱变化的关系. 中国科学: B 辑, 1991, 21 (7): 759-768.

[3] 郑绵平. 盐湖学的研究与展望. 地质评论, 2006, 52(6) : 737-746.

[ 4 ] 郑绵平, 向 军, 魏新俊等. 青藏高原盐湖. 北京: 科学技术出版社, 1989: 1-431.

[ 5 ] 郑绵平, 赵元艺, 刘俊英. 第四纪盐湖沉积与古气候. 第四纪研究, 1998, (4) : 297-307.

[ 6 ] 郑绵平. 论盐湖学. 地球学报, 1999, 20(4) : 395-401.

[ 7 ] 胡东升, 张华京, 李炳元等. 青藏高原腹地湖泊沉积序列与古气候变化. 地质学报, 2000, 74(4): 363-370.

[ 8 ] Zheng MP, Meng YF, Wei LJ. Evidence of the pan-lake stage in the period of $40-28 \mathrm{ka}$ BP on the Qinghai-Tibet Plateau. Acta Geologica Scinca, 2000, 74(2) : 266-272.

[ 9 ] Torgersen T, De deckker P, Chivas AR et al. Salt lakes: a discussion of processes influencing palaeoenvironmental interpretation and recommendations for future study. Palaeogeogr, Palaeoclimatol, Palaeoecol, 1986, 54: 7-9.

[10] Smith GI. Subsurface stratigraphy and geochemistry of late Quaternary evaporates, Searles Lake, California, U. S. Geol Surv Prof Pap, 1979, 1043: 130.

[11] Spencer RJ, Eugster HP, Jones BF. Geochemistry of Great Salt Lake, Utah. II: Pleistocene-Holocene evolution. Geochim Cosmochim Acta, 1985, 49: 739-747.

[12] Bowler JM, Huang Q, Chen KZ et al. Radiocarbon dating of Playa-Lake hydrologic changes: Examples from Northwestern China and central Australia. Palaeogeogr, Palaeoclimatol, Palaeoecol, 1986, 54: 241-260.

[13] Last WM, Slezak LA. The salt lakes of western Canada:a paleolimnological overview. Hydrobiol, 1988, 158: 301-316.

[14] 中国科学院盐湖研究所. 青海柴达木盆地晚新生代地质环境演化. 北京: 科学出版社, 1986: 1-156.

[15] 黄 麒, 陈克造. 七十三万年来柴达木盆地察尔汗盐湖古气候波动的形式. 第四纪研究, 1990, 3: 205-212.

[16] 张彭喜, 张保珍. 柴达木地区近三百万年来古气候环境演化的初步研究. 地理学报, 1991, 46(3) : 326-335.

[17］魏新俊, 姜继学. 柴达木盆地第四纪盐湖演化. 地质学报, 1993, 67(3) : 255-265. 
[18] 刘兴起, 王永波, 沈 吉等. 16000 a 以来青海茶卡盐湖的演化过程及其对气候的响应. 地质学报, 2007, (6): 843-849.

[19] Liu XQ, Dong HL, Jason AR et al. Evolution of Chaka Salt Lake in NW China in response to climatic change during the Latest Pleistocene-Holocene. Quaternary Science Reviews, 2008, 27(7/8) : 867-879.

[20］齐 文, 郑绵平. 西藏扎布耶湖 ZK91-2 钻孔沉积特征与气候环境演化. 湖泊科学, 1995, 7 (2) : 133-140.

[21] 魏乐军, 郑绵平, 刘喜方等. 西藏洞错硼砂芒硝层的发现及其古气候意义. 地质学报, 2002, 76(2): 261-271.

[22] 魏乐军, 郑绵平, 马志邦. 西藏台错盐湖 TT-1 剖面的沉积特征和年代学研究. 地球学报, 2004, 23(4) : 1-10.

[23] 魏东岩, 陈延成, 王鉴津等. 内蒙古伊克昭盟盐湖最近 $23 \mathrm{ka}$ 古气候波动模式的研究. 化工矿产地质, 1995, 17 (4) : 239-247.

[24] 陈延成, 魏东岩, 王鉴津等. 内蒙古伊古昭盟盐湖晚第四纪氧碳同位素记录及古气候研究. 化工矿产地质, 1995, 17(4) : 229-238.

[25] 江德昕, 魏 俊. 内蒙古查干诺尔盐湖晚更新世至全新世狍粉植物与古气候. 沉积学报(增刊), 1997, A12 : 147 152.

［26］春 喜, 王宗礼, 夏敦胜等. 吉兰泰盐湖的形成及指示的环境意义. 盐湖研究, 2008, (3) : 11-18.

[27］耿 㑆, 胡春元, 刘 佳. 吉兰泰地区第四纪湖泊的演变. 干旱区资源与环境, 1989, 3 (2) : 26-33.

[28］耿 㑆, 陈育峰. 吉兰泰盐湖的形成、发育和演化. 地理学报, 1990, 45(3): 341-349.

[29] 郑喜玉. 内蒙古盐湖. 北京: 科学出版社, 1992: 95-210.

[30] 胡春元. 试论吉兰泰盐湖的发育与资源保护问题. 内蒙古林学院学报: 自然科学版, 1998, 20(2) : 54-59.

[31］春 喜. 晚第四纪吉兰泰盐湖古湖面与环境变化研究 [学位论文]. 兰州: 兰州大学, 2006.

[32］庞西否, 胡东生. 近 $22 \mathrm{ka}$ 以来吉兰泰盐湖的环境变化及成盐过程. 中国沙漠, 2009, (2): 193-199.

[33] 郑喜玉, 张明刚, 徐 旭等. 中国盐湖志. 北京: 科学出版社, 2002: 371-374.

[34] 于松升, 白福易, 李浩基. 吉兰泰盐湖资源环境与可持续发展研究. 北京: 科学出版社, 2001: 21-47.

[35] Chung FH. Quantitative interpretation of X-ray diffraction patterns of mixtures. II. Adiabatic principle of X-ray diffraction analysis of mixtures. Journal of Applied Crystallography, 1974, 7: 526-531.

[36] Jin ZD, Wu YH, Zhang XH et al. Role of late glacial to mid-Holocene climate in catchment weathering in the central Tibetan Plateau. Quaternary Research, 2005, 63(2) : 161-170.

[37] Morrill C, Jonathan TO, Julia EC et al. Holocene variations in the Asian monsoon inferred from the geochemistry of lake sediments in central Tibet. Quaternary Research, 2006, 65(2) : 232-243.

[38 ] Shen J, Liu XQ, Wang SM et al. Palaeoclimatic changes in the Qinghai Lake area during the last 18000 years. Quaternary International, 2005, 136: 131-140.

[39] Yang XP, Ma NN, Dong JF et al. Recharge to the interdune lakes and Holocene climatic changes in the Badain Jaran Desert, Western China. Quaternary Research, 2010, 73: 10-19.

[40 ] Liu XQ, Shen J, Wang SM et al. A 16000-year pollen record of Qinghai Lake and its paleoclimate and paleoenvironment. Chinese Science Bulletin, 2002, 47(22) : 1931-1937.

[41] 耿 㑆, 张振春. 内蒙古大贵诺尔全新世湖群地貌特征及其演化. 北京师范大学学报: 自然科学版, 1988,18 (4) : 94-101.

[42] 顾兆炎, 刘嘉麒, 袁宝印等. 12000 年来青藏高原季风变化一一色林错沉积物地球化学证据. 科学通报, 1993, 38 (1) : $61-64$.

[43] Kashiwaya K, Masuzawa T, Morinaga H et al. Changes in hydrological conditions in the central Qing-Zang ( Tibetan) Plateau inferred from lake bottom sediments. Earth and Planetary Science Letters, 1995, 135: 31-39.

[44] Gasse F, Arnold M, Fontes JC et al. A 13 ,000-year climate record from western Tibet. Nature, 1991, 353 : 742-745.

[45] Gasse F, Fontes JC, Campo EV et al. Holocene environmental changes in Bangong Co basin (Western Tibet) :4. Discussions and conclusions. Palaeogeography, Palaeoclimatology, Palaeoecology, 1996, 120: 79-92.

[46] Campo EV, Gasse F. Pollen and diatom inferred climatic and hydrological changes in Sunmxi Co Basion(Western Tibet) since 13,000 yr B. P. Quaternary Research, 1993, 39: 300-313.

[47] Feng ZD, Wang WG, Guo LL et al. Lacustrine and eolian records of Holocene climate changes in the Mongolian Plateau: preliminary results. Quaternary International, 2005, 136: 25-32.

[48］施雅风, 孔昭哀, 王苏民等. 中国全新世大暖期的气候与环境的基本特征. 见: 施雅风编. 中国全新世大暖期气候 
与环境. 北京: 海洋出版社, 1992: 1-19.

[49] Shi YF, Kong ZC, Wang SM et al. Climates and environments of the Holocene Megathermal Maximum in China. Science in China: B, 1994, 37(4) : 482-493.

[50] 吴锡浩, 安芷生, 王苏民等. 中国全新世气候适宜期东亚夏季风时空变迁. 第四纪研究, 1994, 24(1): 24-37.

[51] 秦伯强, 施雅风, 于 革. 亚洲内陆湖泊在 $18 \mathrm{ka} \mathrm{BP}$ 和 $6 \mathrm{ka}$ BP 的水位变化及其指示意义. 科学通报, 1997,42 (24) : 2586-2590.

[52] Jia YL, Shi YE, Wang SM et al. Lake expending events in the Tibetan Plateau since 40 ka BP. Science in China: D, 2001, 44(Suppl. ) : 301-314.

[53] 于 革, 赖格英, 刘 健等. MIS3 晚期典型阶段气候模拟的初步研究. 第四纪研究, 2003, 23(1): 12-24.

[54] 于 革, 薛 滨, 刘 健等. 中国湖泊演变与古气候动力学研究. 北京: 气象出版社, 2001: 42-178.

[55] Harrison SP, Yu G, Tarasov PE. Late Quaternary lake-level record from northern Eurasia. Quaternary Research, 1996, 45: 138-159.

[56] Tarasov PE, Harrison SP. Lake status records from the former Soviet Union and Mongolia: a continental-scale synthesis. Palaeoklimaforschung, 1998, 25: 115-130.

[57] Grunert J, Lehmkuhlb K, Walther M. Paleoclimatic evolution of the Uvs Nuur basin and adjacent areas (Western Mongolia). Quaternary International, 2000, 65/66: 171-192.

[58] 陈发虎, 朱 艳, 李吉均等. 民勤盆地湖泊沉积记录的全新世千百年尺度夏季风快速变化. 科学通报, 2001,46 (17) : 1414-1419.

[59] 陈发虎, 吴 薇, 朱 艳等. 阿拉善高原中全新世干旱事件的湖泊记录研究. 科学通报, 2004, 49(1): 1-9.

[60] Chen FH, Shi Q, Wang JM. Environmental changes docmuenetd by sedimentation of Lake Yiema in arid China since the Late Glaciation. Journal of Paleolimnology, 1999, 22 : 159-169.

[61] Chen FH, Wu W, Holmes JA et al. A mid-Holocene drought interval as evidenced by lake desiccation in the Alashan Plateau, Inner Mongolia, China. Chinese Science Bulletin, 2003, 48(14) : 1401-1410.

[62] Sirocko F, Sarntheim M, Erlenkeuser H et al. Century-scale events in monsoonal climate over the past 24,000 years. $N a$ ture, 1993,364 : 322-324.

[63] Overpeck J, Anderson D, Trumbore S et al. The southwest Indian Monsoon over the last 18,000 years. Climate Dynamics, 1996, 12 : 213-225.

[64] Herzschuh U. Palaeo-moisture evolution in monsoonal Central Asia during the last 50,000 years. Quaternary Science Reviews, 2006, 25 : 163-178. 